The balance between individual and societal pathways is likely to vary from one country to another, from one period to another, and with the size of the areas over which inequality is measured. But regardless of the pathway, the relation between income inequality and population health suggests that reducing health inequalities need not conflict with the desire to raise health standards throughout society. Instead of redistributing a given amount of health or health producing goods in a zero sum game, we can be confident that increased wellbeing among the least well off need not be matched by losses among the rich.

1 Brunner E, Marmot M. Social organization, stress, and health. In: Marmot MG, Wilkinson RG, eds. The social determinants of health. Oxford: Oxford University Press (in press)

2 Lynch J, Kaplan GA, Pamuk ER, Cohen RD, Heck KE, Balfour JL, et al. Income inequality and mortality in metropolitan areas of the United States. Am J Pub Health 1998;88:1074-80.

3 Wilkinson RG. The culture of inequality In: Kawachi I, Kennedy B, Wilkinson RG, eds. The society and population health reader. Vol 1. Income inequality and health. New York: New Press (in press).

4 Wallace R, Wallace D. A plague on your houses. New York: Verso, 1998.

\title{
Effect of station design on death in the London Underground: observational study
}

\author{
T J Coats, D P Walter
}

Injury and death after a fall or jump under a train (known colloquially as a "one under") are common on the London Underground. ${ }^{1}$ Emergency teams noticed that both severity of injury and survival seemed to be related to the design of the station, with a drainage pit (often called the "suicide pit") giving a protective effect. This pit is located under the railway tracks for the length of the platform in about half of underground stations. It is usually about a metre deep and was originally intended to drain water away from the platform.

We carried out this study to assess mortality in patients hit by London Underground trains at platforms with and without a drainage pit.

\section{Methods and results}

For each incident from January 1996 to March 1997 the "record of incident" made in compliance with the Railway Regulations Act of 1893 was retrospectively examined. The platform of each incident and the outcome (lived or died) were recorded. The presence of a drainage pit was ascertained from the station manager or by personal inspection. The outcome with and without a drainage pit was compared with Fisher's exact test.

Fifty eight cases occurred over the 15 months, but the exact platform concerned could not be ascertained for five incidents. Thirty three patients died (overall mortality $57 \%$ ). The table shows that the mortality was $44 \%$ for platforms with a pit compared with $76 \%$ for platforms without a pit. This difference was significant $(\mathrm{P}=0.026)$

\section{Comment}

This study shows that the presence of a pit halves the number of deaths in patients who are hit by a train. The

Outcome in 58 incidents according to whether platform did or did not have pit

\begin{tabular}{lcccc} 
& Pit & No pit & Unknown & Total \\
\hline Dead & 14 & 16 & 3 & 33 \\
\hline Alive & 18 & 5 & 2 & 25 \\
\hline
\end{tabular}

overall mortality (at $57 \%$ ) was similar to the previously reported figures of $55 \%{ }^{2}$ and $45 \%{ }^{1}$ Many attempts have been made to reduce the number of deaths on the London Underground. ${ }^{3-5}$ The association between the pit and increased survival ${ }^{2}$ is purely fortuitous as pits were introduced for engineering reasons. The pit increases the clearance between the train and the ground, probably allowing a casualty to fall away from the train's wheels. Even when a pit is present, if the casualty has not fallen into it then he or she is unlikely to survive.

In the design of rolling stock little attention is paid to the interaction between a human body and the train. New carriages at present being introduced on the Jubilee line have less ground clearance, and therefore there is even less room for a body to escape the wheels. The ultimate method of preventing death under trains is the complete separation of moving trains and passengers by the introduction of sliding doors along the platform edge that open only when the train has come to a halt. This feature has been incorporated into some new stations but would probably be prohibitively expensive to introduce at existing stations.

Being hit by a train is an important cause of death from trauma in London, but the presence of a pit under the rails halves the mortality. The mechanics of the interaction of the human body with the train are poorly studied, and so present rolling stock and stations are not designed to maximise survival.

Contributors: TJC initiated the study, helped develop the method, analysed the data, and cowrote the paper. He is the guarantor of the paper. DPW helped develop the method, collected the data, and cowrote the paper.

Funding: None.

Competing interests: None declared.

Cocks R. Study of 100 patients injured by London Underground train 1981-6. BMJ 1987;295:1527-9.

2 O'Donnell I, Farmer R. The epidemiology of suicide on the London Underground. Soc Sci Med 1994;38:409-18.

3 Clarke R, Poyner B. Preventing suicide on the London Underground. Soc Sci Med 1994;38:443-6.

4 Myers C. Man fall under train. Transactions of the Association of Independent Medical Officers 1963;13:93-5.

5 Johnstone D, Waddell J. Death and injury patterns: Toronto subway system 1954-1980. J Trauma 1984;24:619-22.

(Accepted 29 July 1999)

\section{St Bartholomew's and the Royal London School of Medicine, Royal London Hospital, London E1 1BB \\ $\mathrm{T} J$ Coats senior lecturer in accident and emergency \\ London Helicopter Emergency Medical Service, Royal London Hospital D P Walter specialist registrar in accident and emergency \\ Correspondence to: Mr Coats t.j.coats@mds. qmw.ac.uk}

BMJ 1999;319:957 